\title{
Beam-to-Beam Connection of Precast Concrete Structures: State of the Art
}

\author{
Kristiyanto Hery ${ }^{1,2, *}$, Triwiyono Andreas ${ }^{2}$, Muslikh$^{2}$, and Saputra Ashar ${ }^{2}$ \\ ${ }^{1}$ Civil Engineering Department of Cokroaminoto University, Indonesia \\ ${ }^{2}$ Civil and Environmental Engineering Department of Gadjah Mada University, Indonesia
}

\begin{abstract}
The use of precast concrete is known to improve productivity, quality control, and cost efficiency in reinforced concrete structure. The Connection is the most important aspect of precast concrete structures. The connection transfers force between the precast components, determine strength, stiffness, and ductility of the whole structure. Providing joint in the beam-column connection region always cause difficulties during the erection stage. Relocation of the connection at a certain distance from the column to the beam span is an alternative solution that creates the beam-to-beam connection. It will be much easier to assemble the connection that consists of some joints. Research and application of the precast concrete beam-to-beam connection details have published since 1975. This paper reviews the state of the art of research and practical application of beam-to-beam connection system related to connection models, joint locations, and details. It concluded from the review that the developing research leads to improve the performance of earthquake resisting structures
\end{abstract}

\section{Introduction}

Precast concrete structural elements (e.g., beams, columns, wall panels, and floor units) are fabricated, transported to construction sites, lifted and assembled in place. Precast concrete structures widely used in some countries with high seismicity. A large number of studies related to the earthquake-resistant structural system have carried in the United States, New Zealand, Japan and elsewhere. The first part of this study focuses on the development of emulative connections, which aims to ensure that the precast concrete structures would be comparable to equivalent monolithic reinforced concrete structures. The introduction of jointed systems has shifted towards this connection concept and offers better-performing concrete structures [1].

The main advantages of precast concrete structures are the possible increase in construction speed and improve productivity, quality control, and cost efficiency. Noteworthy is an economical and effective way of combining precast concrete elements to resist seismic forces, needs to be done with small tolerances, high-quality control, and increased crane capability to lift heavy precast concrete units [2].

\section{Precast Concrete Connections}

The structure of precast concrete buildings consists of several types of major structural systems incorporated in different ways to obtain effective and adequate structures to meet the specific needs of buildings. Commonly used systems are beam and column systems, floor and roof systems, bearing wall systems, and facade systems [3].

The system is shown in Fig. 1 forms the basis of the skeletal frame. The connections in these systems are: beam to column, beam to beam, column to column, and column to the base.

The Connection is the most important aspect of precast concrete structures. The connection transfers force between the precast components, determine strength, stiffness, and ductility of the whole structure. Failure on one joint should not cause structural instability.

* Corresponding author: herykristiyanto@ucy.ac.id 


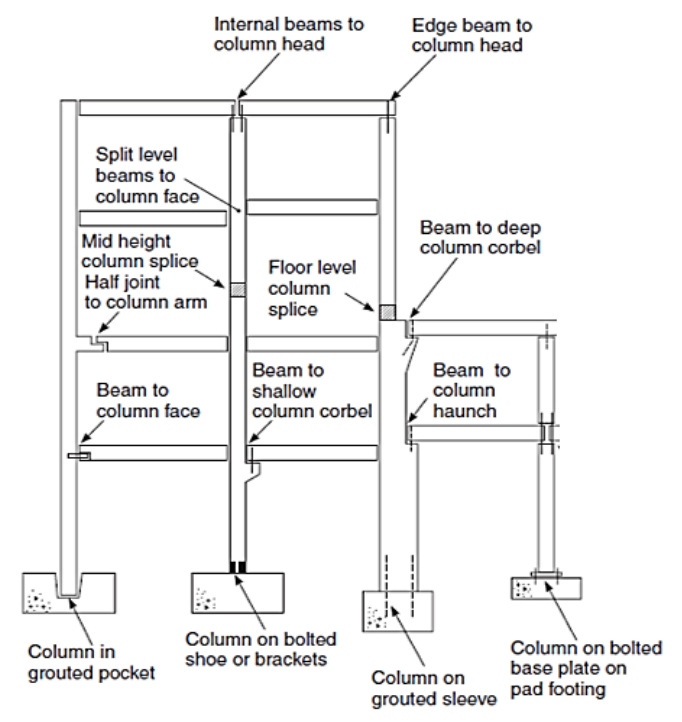

Fig. 1. Precast connections [4].

\subsection{Precast Frame System}

Precast frame systems can design in two categories, with a ductile or a strong connection. In the ductile connection, the bending yielding is expected to occur in the connection area. The connection may be designed to develop yields in a location not adjacent to the joint.

Whereas in the strong connection the bending yield may only occur on the structural part of the precast element outside the joint [5]. Fig. 2 shows a strong connection example.

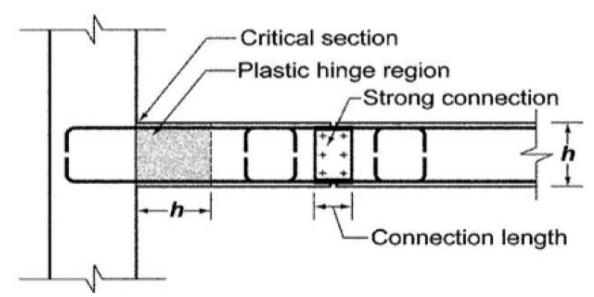

(a) Beam-to-beam connection

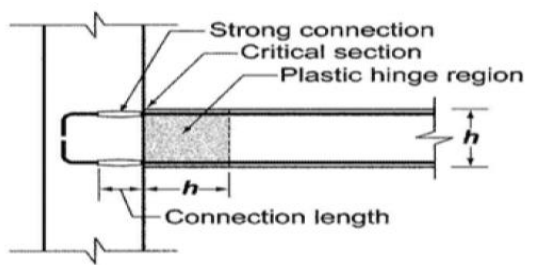

(b) Beam-to-column connection

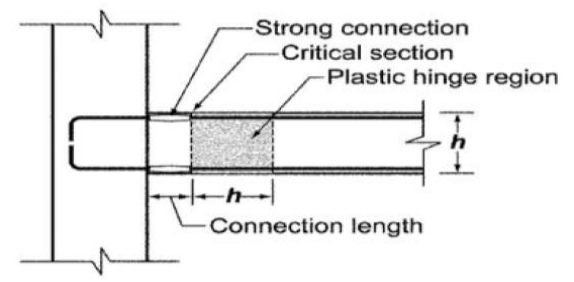

(c) Beam-to-column connection
The location of the strong connection should be chosen carefully to avoid concentration of strain that may produce premature cracking of the reinforcement.

\subsection{Precast Concrete Connection in Moment Resisting Frame}

The moment resisting frame of the precast concrete structures divided into two types, monolithic equivalent systems, and jointed systems, based on differences of connection system between precast concrete elements $[1,6]$.

\subsubsection{Monolith equivalent system}

The connection between precast concrete elements of an equivalent monolith system can divide into two types: a strong connection with limited ductility and ductile connection.

Monolith equivalent systems with strong connections designed to be strong enough so that yielding not occurs at the connections. The connection stays in the elastic condition when the structure provides the ductility required at the time of the earthquake.

Ductile connections on monolith equivalent systems designed with longitudinal bars or bonded tendons within the connection area which is expected to enter the post-elastic region in large earthquakes.

\subsubsection{Joint system}

The connection between precast concrete elements of the joint system can divide into two types: limited ductility connection and ductile connection.

Limited ductile connections of joint systems, usually a dry connection formed by bolting or welding of reinforcement or plate or steel insertion. These connections behave as if they are not part of a monolith construction and generally have limited ductility or elastic behavior.

Generally, ductile connections of joint systems are a dry joint with unbounded pre-stressed tendons used to connect precast concrete elements. The hybrid system uses a dry joint that incorporates unbonded pre-stressed tendons and longitudinal bars at the moment resisting frame, or unbonded pre-stressed tendons and energy dissipation devices (e.g., flexible steel plates or friction devices).

Three Precast concrete systems designed for weak beamstrong column behavior commonly used in Japan and New Zealand shown in Fig. 3 [1,2,6,7].

Fig. 2. Strong connection examples [5] 


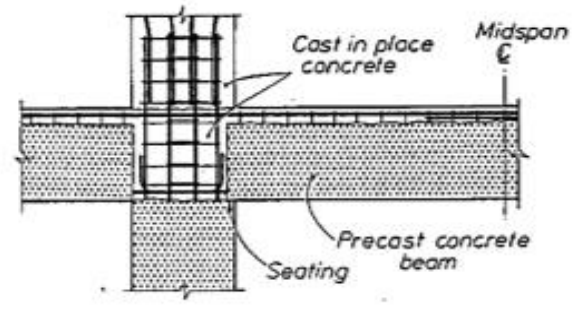

(a) System 1 - precast beam units between colum

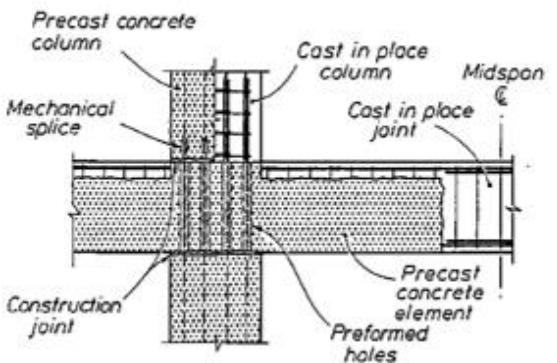

(b) System 2 - precast beam units through colums

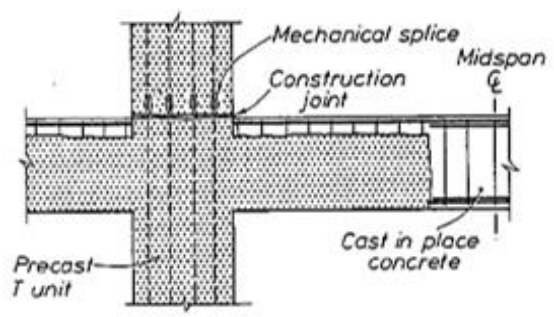

(c) System 3 - precast $T$ or cruciform units

Fig 3. Moment resisting system in New Zealand [7]

System 1 in Fig. 3(a), the precast beam is placed between the columns and occupied on the concrete cover of the lower column. The lower reinforcement on each beam extends outward forming the hook for the anchor on the beam-column joint.

System 2 in Fig. 3(b), connecting the beam-tocolumn in the joint region. Plastic joints can be detailed to occur on beams or outside of columns. Precast beams placed on thin steel of 10 to $25 \mathrm{~mm}$ thickness form a joint. The longitudinal reinforcement of the column penetrates through the vertical holes on the precast beam and protrudes above the surface. The holes in the precast element formed by corrugated steel pipes, similar to those used for tendon reinforced concrete structures. Vertical hole and horizontal joint construction at the base of the precast beam is grouting together. A precast concrete column then positioned above the precast element by using vertical grouting to connect the vertical bars of the column. Figure 4 shows some aspects of building construction utilizing this system.

System 3 of Fig. 3(c), uses a T-shaped column. The vertical bar of the columns is joined using grouted steel sleeves.

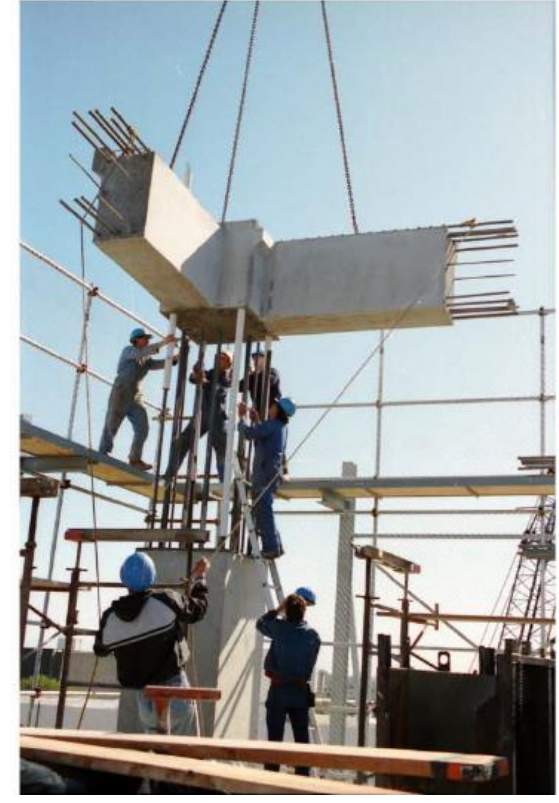

Fig. 4. Aspects of building construction utilizing $[1,6]$

\section{Beam-to-Beam Connections}

Providing joint in the beam-column connection region always cause difficulties during the erection stage. The beam-column connection subjected to reserve bending moment and shear force, be vulnerable to seismic actions [8]. Installing beam-to-beam connections is relatively easier than beam-column connections to be alternative connection systems

Ten details of beam-to-beam connection were published by the Society for Studies on the use of Precast Concrete (Stupre) in early 1975 [9]. The details of the beam connections to beams developed by Stupre include beam-to-beam connections with connecting rods and welds on the main reinforcement.

Beam-to-beam connection with connecting rod or high-quality pull rod is made at both ends and connected to a connecting rod or a high-quality pull rod (Fig. 5(a)). This connection can transfer large vertical and horizontal styles. If the connecting rod placed on the top and bottom of the beam, moments with a certain quantity may also transfer.

The main reinforcement protruded outward and welded in the beam-to-beam connection. After the reinforcement welded to other, then a concrete casting is performed (Fig. 5(b)). Connections can transfer a considerable vertical force, horizontal force and moment, when welding and cast concrete are of good quality. To increase the vertical shear distribution, the edges of the beams should be either rough or grooved. 


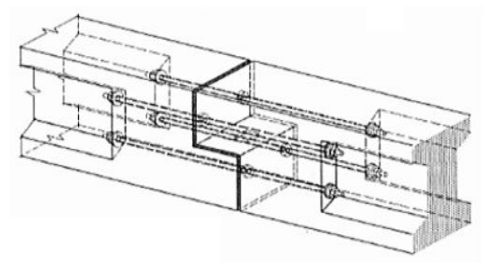

(a) Connection with rod

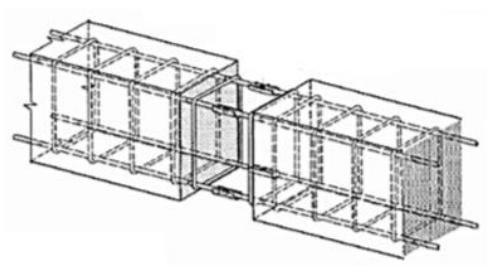

(b) Welded on main reinforcement

Fig. 5. Detail of beam-to-beam connections [9]

\subsection{Beam-to-beam connection in the middle of the span}

Restrepo et al. [7] conducted a study of precast concrete connection at the beam middle-span with several different details. The objective of the study was to evaluate the performance of the connection in transferring the force at the beam middle-span, to observe the effect of the connection on the critical area at the time of the formation of the plastic hinges. Connection types used include middle-span connections using 180-degree overlapping hooks and 90-degree double hooks.

The middle-span connections consisting of the overlapping hook of I80-degrees begin at $1.46 \mathrm{~d}$ from the face of the column, where $d$ is the height of the beam. The four short transverse bars with the same diameter as longitudinal bars are placed in contact on the inside of the hook arch to improve the condition anchor (Fig. 6).

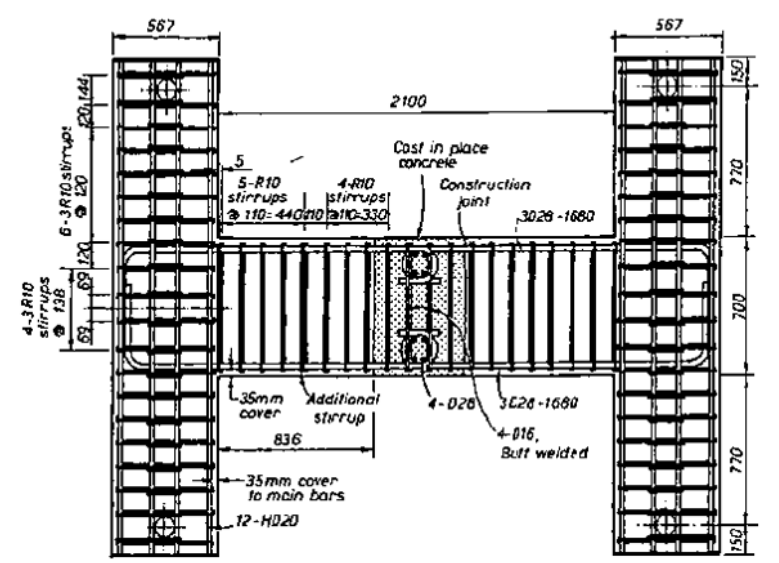

In general, the test results show that the connection model in the middle-span with overlapping bending rebar in 180-degree performs well. The test is performed at least two cycles with ductility factor $\mu_{\Delta}=+6$ and a standard deviation of 2.4 percent or more, maintaining at least 80 percent of the maximum lateral load (Fig. 7). The deformation of the cracked shear causes the collapse at the end of the beam near the column face (Fig. 8).

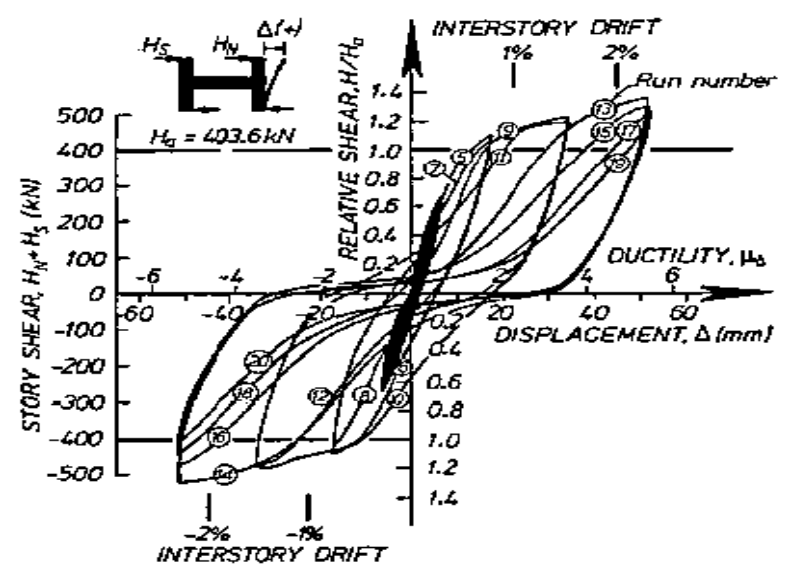

Fig. 7. Test result [7]

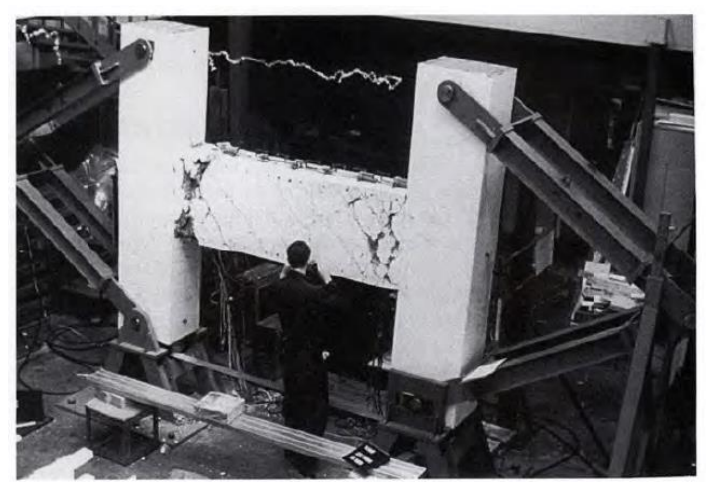

Fig. 8. Cracking at specimen [7]

Welding longitudinal reinforcement can also make Beam-to-beam connections. Welding is done thoroughly to ensure the quality of welding. Fig. 9 show the detail of the welded joint.

Fig. 6. Detail construction system 2 [7] 


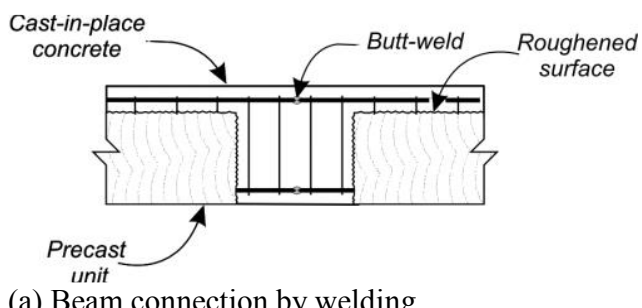

(a) Beam connection by welding

(b) Set-up

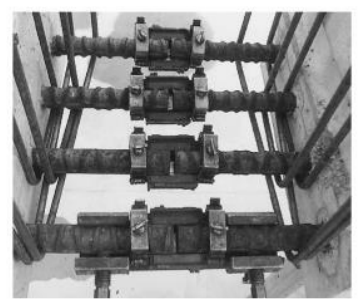

(c) Welded bars

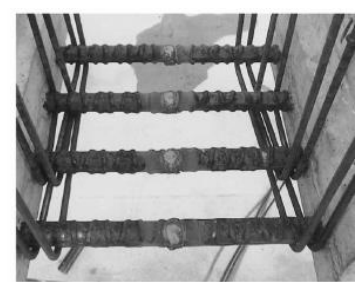

Fig. 9. Example of a welded connection in a building in Japan (courtesy of F. Watanabe) [6]

\subsection{Beam-to-beam connection near column face}

\subsubsection{Concrete beam connection}

Ersoy and Tankut [10] tested the precast concrete beam connection with dry joints for high rise buildings in the quake areas under reserved cyclic loading (Fig. 10).

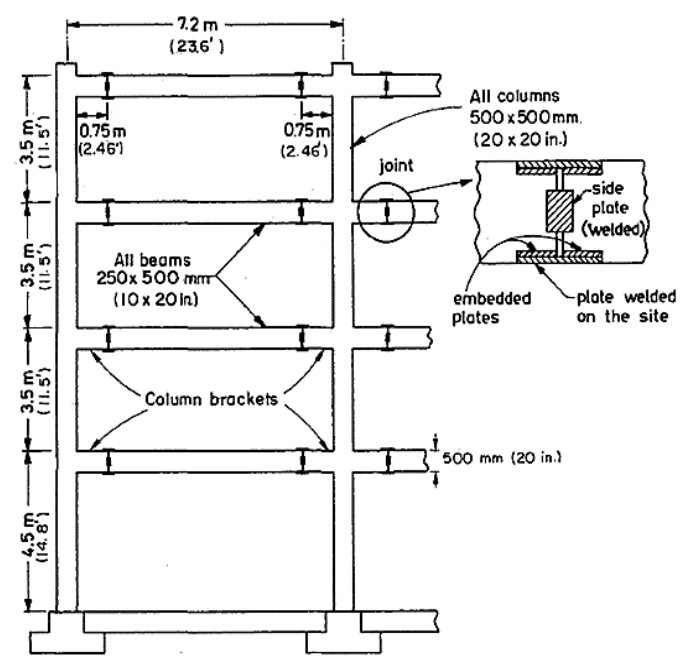

Fig. 10. Dry joints for high rise buildings [10]

This joint consists of two steel plates, at the top and bottom of the beam with an anchor welded on the steel plate at the end of the beam to joined (Fig. 11). The design later repaired by adding a side plate. Five specimens with these joints and two monolith reference specimens were tested with reserved cyclic loading to study their behavior due to earthquake forces. The main variables are the addition of side plate and the difference in distance between the ends of the beam to be joined.

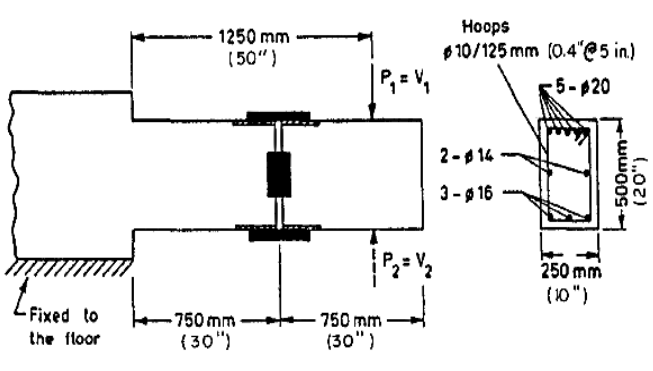

Bor diometers, $\phi 14=0.56 \mathrm{in}, \phi 16=0.64 \mathrm{in}, \phi 20=0.80 \mathrm{in}$.

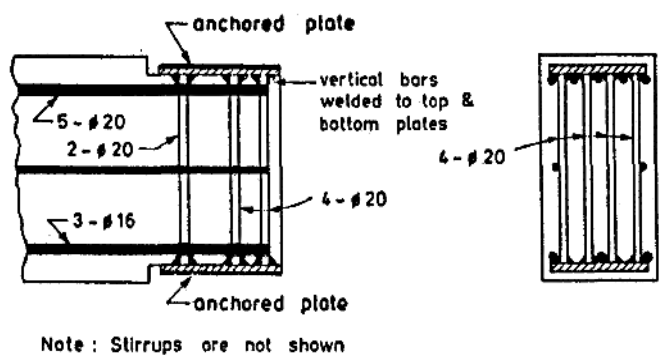

Fig. 11. Detail of connection consists of steel plate [10]

In Table $1, M_{\text {cal }}$ is the maximum moment at the root of the test object calculated using the basic assumptions listed in the ACI rule, section 10.2. $\delta_{y}$ is the deflection of the measurement result at the end when yielding of the upper longitudinal rebound at the root of the specimen. The maximum displacement, $\delta_{u}$, is the net deflection of the measuring apparatus corresponding to 85 percent of the maximum moment attained. The ratio, $\delta_{u} / \delta_{y}$ given in the table is called the "ductility factor of displacement" and is equal to the maximum displacement ratio for the displacement associated with the yield in the tensile reinforcement.

Table 1. Summary of test result [10]

\begin{tabular}{|c|c|c|c|c|}
\hline \multirow{2}{*}{ Ratio } & \multicolumn{4}{|c|}{ Specimen designation } \\
\cline { 2 - 5 } & TR1 & TR2 & TP4 & TP5 \\
\hline$M_{\text {test }} / M_{\text {cal }}$ & 1.03 & 1.09 & 1.12 & 1.13 \\
\hline $\begin{array}{c}\text { Displacement } \\
\text { ductility } \delta_{u} / \delta_{y}\end{array}$ & 5.0 & 6.0 & 6.0 & 6.0 \\
\hline
\end{tabular}

As can be seen from Table 1, all monolithic test specimens (TR1 and TR2) and specimens with additional side plates (TP4 and TP5) reach the maximum bending capacity according to the count. Displacement ductility $\left(\delta_{u} / \delta_{y}\right)$ of the specimen with the side plate is proportional to the monolithic specimen.

Korkmaz and Tankut [11] tested six beam-to-beam connections under reserved cyclic loading as an 
earthquake force simulation (Fig. 12(a)). The first test object (MR1) is cast monolithically, used as a reference specimen. The second test object (PO1) is the original precast specimen. The other four test objects have some improvement compared to the PO1 specimen. The beam test object connected around the zero moment region. Two alternate connections are used for the upper beam reinforcement, i.e., connection with overlapping and weld (Fig. 12(b)). After reinforcement between the beams is connected, a concrete casting performed.

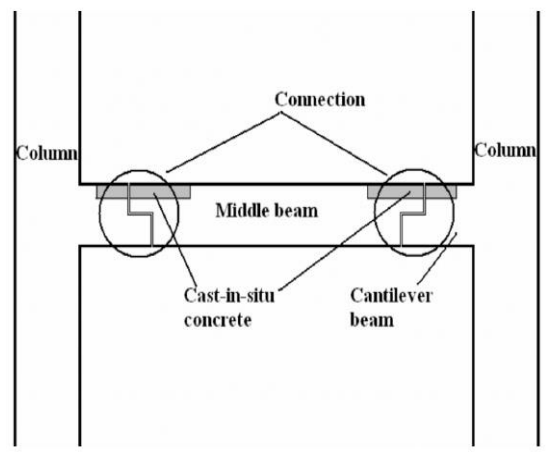

(a) The connection of the precast frame

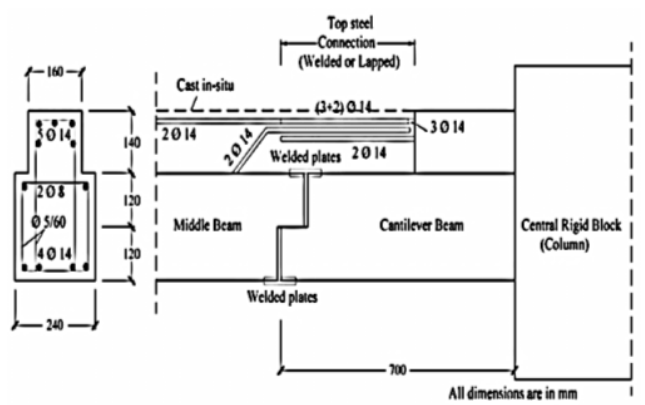

(b) Dimension and detail of specimen

Fig. 12. Precast concrete beam connection [11]

From Table 2. Subscript 'y' denotes the beginning of the yield, 'max' shows the maximum value, 'R' indicates the measured value for specimens use as a reference (MRI) and ' 85 ' indicates the value appropriate to $85 \%$ of the maximum load $(0,85 \times$ Pmax $)$. In the table, ' $\mathrm{P}$ ' is the end load and ' $\mathrm{U}$ ' is the ends deflection.

Table 2. The measured result corresponding to ultimate and yield [11]

\begin{tabular}{|c|c|c|c|c|}
\hline Specimen & $\begin{array}{c}\boldsymbol{P}_{\max } \\
(\mathbf{k N})\end{array}$ & $\begin{array}{c}\boldsymbol{U}_{\boldsymbol{y}} \\
(\mathbf{m m})\end{array}$ & $\begin{array}{c}\boldsymbol{U}_{\mathbf{8 5}} \\
(\mathbf{m m})\end{array}$ & $\begin{array}{c}\boldsymbol{\lambda}_{\boldsymbol{d}} \\
\left(\mathbf{U}_{\mathbf{8 5}} / \mathbf{U} \mathbf{y}\right)\end{array}$ \\
\hline MR1 & 102.1 & 12.01 & $>115$ & $>9.58$ \\
\hline PO1 & 67.8 & 13.14 & 38.05 & 2.89 \\
\hline PM1 & 99.2 & 13.14 & $>118$ & $>8.98$ \\
\hline
\end{tabular}

In PM1, the upper longitudinal reinforcement coupled to the weld, and the lower steel joint also welded along $60 \mathrm{~mm}$. The joint has the same capacity as the monolith connection (higher than $90 \%$ compared to monolith). The shear deformation that occurs in the junction area is very low. Plastic joints occur at the beginning of the cantilever, and just slight damage occurs in the connection area (Fig. 13). Ductility of PM1 is quite satisfactory $\left(\lambda_{d}>8.98\right)$.

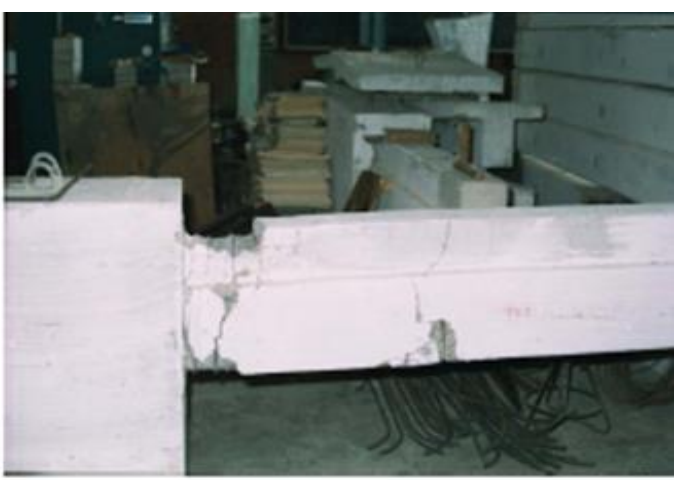

Fig. 13. Damage in specimen PM1 [11]

Khoo et al. [8] tested connections on precast concrete frames where the connection is made to the beam span and kept away from the column surface and does not coincide with the plastic joint area of the beam caused by the earthquake, see Fig. 14(a). Unit 1 is made monolithically to be a control test object. The unit 2 joint is composed of a 90-degree hook (Fig. 14(b)), where all the longitudinal bars connected by using such hooks at a distance of about $1.8 \mathrm{~d}$ from the column face, where $\mathrm{d}$ is the effective height of the beam. The 3 unit connection consists of a 180-degree hook at a distance of $1.75 \mathrm{~d}$ from the column surface (Fig. 14(c)).

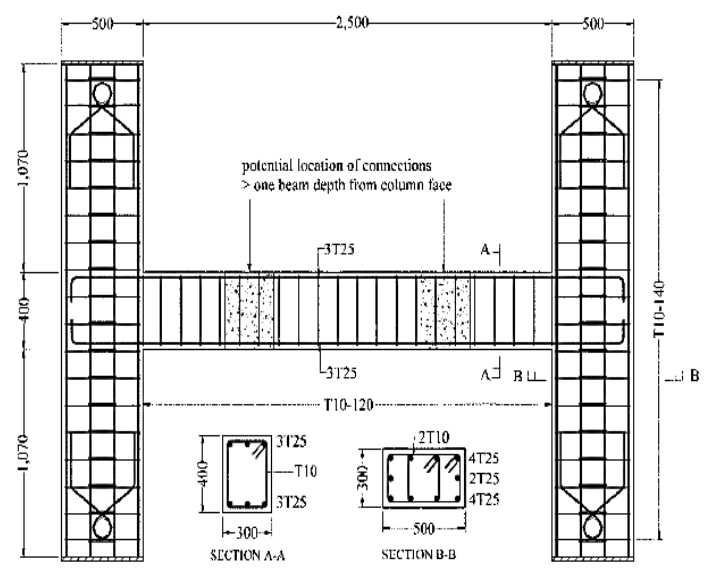

(a) Connection kept away form column surface

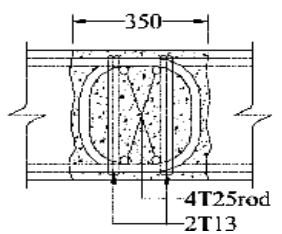

(b) Unit 2

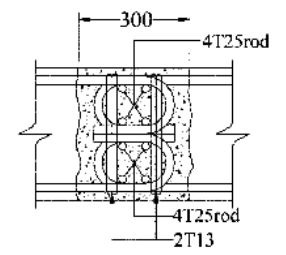

(c) Unit 3
Fig. 14. Detail of specimen [8]

All specimens loaded with quasi-static as simulated earthquake loads. The "strong connection" approach 
adopted in this study is crucial in achieving elastic behavior of the joints allowing the development of yielding strength in reinforcement in the plastic hinges region.

Fig. 15 shows the load-displacement envelope on the precast concrete connection and the control specimen. In Unit 3 precast linked with 180 -degree hooks, it shows a nearly perfect correlation with the control specimen (unit 1) on stiffness and strength.

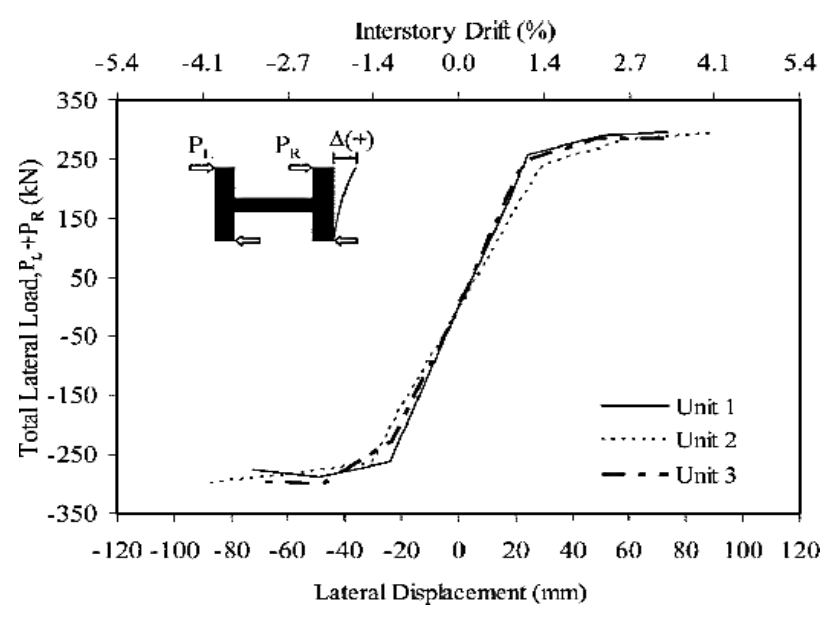

Fig. 15. The load-displacement envelope [8]

All the frames can load on a ductility factor of at least 3; this proves the ability of the ductility-limited behavior. Regarding strength, flexural strength capacity can maintain the level of deviation exceeds $2.5 \%$. This connection model is capable of providing adequate earthquake resistance in areas with low to moderate earthquakes.

The precast concrete frame specimens have shown the formation of plastic joints at the end of the beam near the face of the column along "d" the effective depth of the beam. The failure of all precast connection specimens identified caused by large shear deformation in the region of the plastic joints.

\subsubsection{Concrete beam to steel beam connection}

Ogden and Henley [12] provides a detailed connection between steel beams with existing concrete beams using a series of steel plate and bolts as shown in Fig. 16.
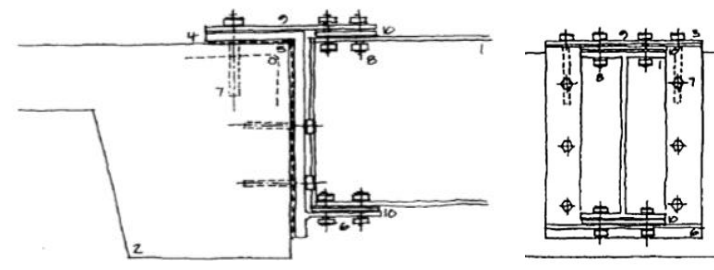
1. Steel beam
6. Seating
2. Concrete beam
7. Expanding anchor
3. Lihgt connection plate
8. HFSG
4. Heavy connection
9. Bolted plat
5. Soft pack on edge of salb
10. Shims

Fig. 16. Concrete beam to steel beam connection [12]
Yang et al. (2010) tested a precast concrete hybrid beam system which is a connection of $\mathrm{H}$-steel beam and reinforced concrete beams (Fig. 17(a)). Three beam test objects were tested to collapse to explore the strength and limitations of precast concrete beam systems in bending transfers. The three specimens of precast hybrid concrete beam tested were $\mathrm{S}$ test specimens in the form of control beams, and $\mathrm{U}$ and $\mathrm{P}$ specimens were used to appraise the effects of in-situ concrete and the effect of the pre-stressing force on the bending behavior of the beam.

At the end of the reinforced concrete beam embedded partly from one end of the $\mathrm{H}$ steel beam. Bottom wing and $\mathrm{H}$-steel beam body are embedded into concrete with some stud bolts to prevent slip between a reinforced concrete beam and $\mathrm{H}$ steel beam. The precast concrete beam connection system proposed has three parts: the reinforced concrete beam, the steel composite section $\mathrm{H}$ and the reinforced concrete, and the $\mathrm{H}$ steel beam. [13]

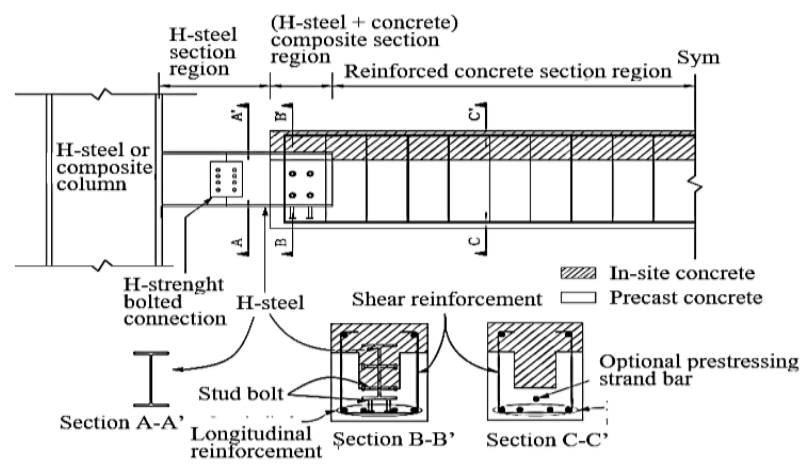

(a) Detail specimens

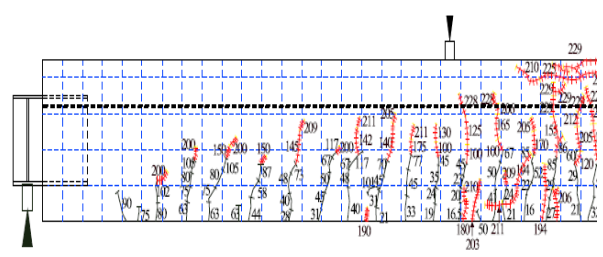

(b) Crack propagation on specimens $U$

Fig. 17. Detail of specimen and crack propagation [13]

No cracks were observed around $\mathrm{H}$ steel in the composite area until the beam collapsed (Fig. 17(b)). The value of the strain measured at the posterior of the $\mathrm{H}$-steel wing is faithful to the predicted calculation by using elasticity theory. These results indicate that the $\mathrm{H}$ steel in precast concrete beam system has integrity in transferring loads.

Yang et al. (2016) tested a system of connections between precast concrete beams, and Hybrid $\mathrm{H}$ steels established as simple ductile connections (Fig. 18). The developed beam connection system has three distinct parts: precast reinforced concrete, joint, and $\mathrm{H}$-steel. Five test beam connection objects were tested one-point concentrated top loads at the middle of the span under reversed cyclic loading.

The test specimen designed as $\mathrm{H} 0.25, \mathrm{H} 0.5$, and $\mathrm{H} 1.0$ are used to investigate the effect of the connection 
location on bending beam behavior. P0.5 and S0.5 are used to study pre-stressing styles and the impact of the longitudinal upper cross-section steel joints to provide the stress, respectively. Stress is acting on the lower and upper longitudinal reinforce bars transferred to the lower and upper wings of steel $\mathrm{H}$ through elbow L [14].

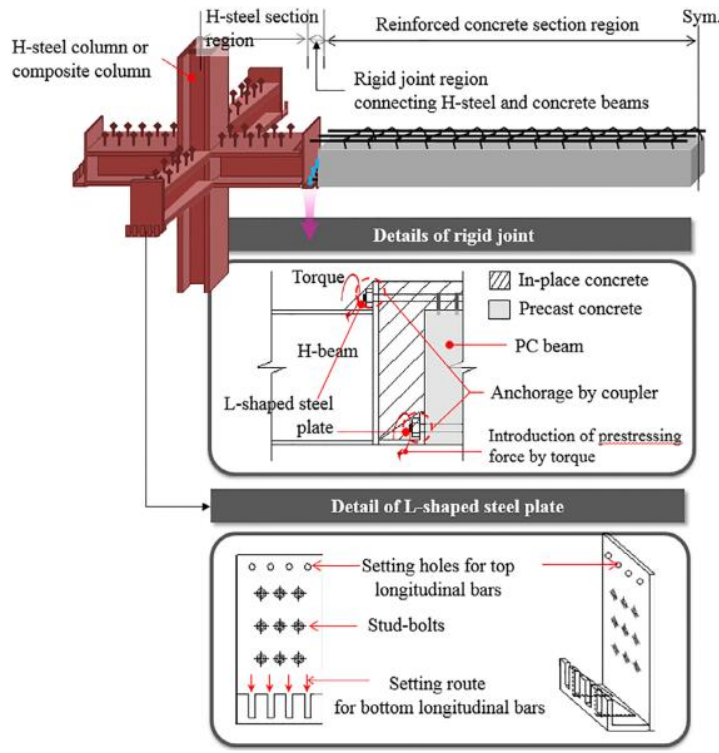

Fig. 18. Connection detail of the concrete beam to the steel beam [14]

In general, based on crack propagation measures, cyclic-displacement load curves, consistency between records and strain distribution calculations, and the suitability of maximum loads with load counts of collapse, the proposed joints for connecting steel $\mathrm{H}$ and reinforced concrete beams may be considered as rigid connections within resist the working moments.

\section{Conclusion}

The Beam-to-beam connection of precast concrete designed with careful design concepts and detail as well as careful fabrication and installation will result in highperformance structures that resist earthquake.

The research and practice using beam-to-beam connections on the precast concrete show more growth. The connection can design according to code for use in areas with high seismic hazards.

Installing beam-to-beam connection that is relatively easier than a beam-column connection, will likely increase its use in the coming years.

The highest gratitude expressed to the Ministry of Research, Technology and Higher Education are cooperating with Lembaga Pengelola Dana Pendidikan (LPDP) from Ministry of Finance who has given the scholarship in the program of Beasiswa Unggulan Dosen Indonesia-Dalam Negeri (BUDI$\mathrm{DN})$.

\section{References}

1. Y. C. Kurama, S. Sritharan, R. B. Fleischman, J. I. Restrepo, R. S. Henry, N. M. Cleland, S. K. Ghosh, P. Bonelli, Seismic-Resistant Precast Concrete Structures: State of the Art, Journal of Structural Engineering, ASCE (2018)

2. R. Park, The FIB State-of-the-Art Report on the Seismic Design of Precast Concrete Building Structures, Pacific Conference on Earthquake Engineering (2003)

3. FIB, Structural Connections for Precast Concrete Buildings, Bulletin 43, International Federation for Structural Concrete, Stuttgart (2008)

4. K. S. Elliot, Precast Concrete Structures, Oxford (2002)

5. ACI 318-11, Building Code Requirements for Structural Concrete and Commentary, ACI Committee 318 (2011)

6. FIB, Seismic Design of Precast Concrete Building Structures, Bulletin 27, International Federation for Structural Concrete, Stuttgart (2003)

7. J. I. Restrepo, R. Park, A. H. Buchanan, Test on Connections of Earthquake Resisting Precast Reinforced Concrete Perimeter Frames of Building, PCI Journal (1995)

8. J. H. Khoo, B. Li, W. K. Yip, Test on Precast Concrete Frames with Connections Constructed Away from Column Faces, ACI Structural Journal (2006)

9. Stupre, Precast Concrete Connection Detail, Society for Studies on the use of Precast Concrete, Netherlands (1978)

10. U. Ersoy, T. Tankut, Precast Concrete Members With Welded Plate Connections Under Reserved Cyclic Loading, PCI Journal (1993)

11. H. H., Korkmaz, T. Tankut, Performance of a Precast Concrete Beam-to-Beam Connection Subject to Reserved Cyclic Loading, Engineering Structures 27 (2005)

12. R. G. Ogden, R. Henley, Connections between Steel and Other Materials, The Steel Construction Institute, Oxford Brookes University (1996)

13. K. H. Yang, M. H. Oh, M.H. Kim, H. C. Lee, Flexural Behavior of Hybrid Precast Concrete Beams with H-Steel Beams at Both Ends, Engineering Structures 32 (2010)

14. K. H. Yang, E. A. Seo, S. H. Hong, Cyclic Flexural Tests of Hybrid Steel-Precast Concrete Beams with Simple Connection Elements, Engineering Structures 118 (2016) 